\title{
Malarial pigment hemozoin and the innate inflammatory response
}

\author{
Martin Olivier ${ }^{1,2}$ *, Kristin Van Den Ham ${ }^{1,2}$, Marina Tiemi Shio ${ }^{1,2}$, Fikregabrail Aberra Kassa ${ }^{1,2}$ and \\ Sophie Fougeray ${ }^{1,2}$
}

${ }^{1}$ Department of Medicine, McGill TB International Centre, Research Institute of the McGill University Health Centre, McGill University, Montréal, OC, Canada

${ }^{2}$ Department of Microbiology and Immunology, McGill TB International Centre, Research Institute of the McGill University Health Centre, McGill University, Montréal, OC, Canada

Edited by:

Jorg Hermann Fritz, McGill University,

Canada

Reviewed by:

Koichi S. Kobayashi, Texas A\&M

Health Science Center, USA

Robert Adam Harris, Karolinska

Institutet, Sweden

\section{*Correspondence:}

Martin Olivier, Department of

Microbiology and Immunology, McGill

TB International Centre, Research

Institute of the McGill University

Health Centre, McGill University, Duff

Medical Building, Room 600, 3775

University Street, Montréal, $Q C$

H3A2B4, Canada

e-mail: martin.olivier@

mcgill.ca
Malaria is a deadly infectious disease caused by the intraerythrocytic protozoan parasite Plasmodium. The four species of Plasmodium known to affect humans all produce an inorganic crystal called hemozoin $(\mathrm{HZ})$ during the heme detoxification process. $\mathrm{HZ}$ is released from the food vacuole into circulation during erythrocyte lysis, while the released parasites further infect additional naive red blood cells. Once in circulation, $\mathrm{HZ}$ is rapidly taken up by circulating monocytes and tissue macrophages, inducing the production of proinflammatory mediators, such as interleukin-1 $\beta$ (IL-1 $1 \beta)$. Over the last few years, it has been reported that $\mathrm{HZ}$, similar to uric acid crystals, asbestos, and silica, is able to trigger IL-1 $\beta$ production via the activation of the NOD-like receptor containing pyrin domain 3 (NLRP3) inflammasome complex. Additionally, recent findings have shown that host factors, such as fibrinogen, have the ability to adhere to free $\mathrm{HZ}$ and modify its capacity to activate host immune cells. Although much has been discovered regarding NLRP3 inflammasome induction, the mechanism through which this intracellular multimolecular complex is activated remains unclear. In the present review, the most recent discoveries regarding the capacity of $\mathrm{HZ}$ to trigger this innate immune complex as well as the impact of $\mathrm{HZ}$ on several other inflammatory signaling pathways will be discussed.

Keywords: malaria, hemozoin, macrophages, signaling, inflammasome

\section{INTRODUCTION}

Malaria is an infection that affects 216 million individuals worldwide. Every year, approximately 700,000 people succumb to this devastating disease (1). The protozoan parasite Plasmodium is the etiological agent of malaria and it is transmitted during the blood meal of a female Anopheles mosquito (2). Of all the Plasmodium species infecting humans, $P$. falciparum is the most virulent and its pathology is characterized by severe anemia or the development of cerebral malaria, generally leading to death if left untreated (3). The Plasmodium life cycle within its mammalian host includes a non-pathological liver stage followed by red blood cell (RBC) invasion by merozoites, the infectious form of the parasite, which initiates the symptomatic intraerythrocytic cycle (4). Classical malaria paroxysms are characterized by periodic fevers and chills, which are synchronized with the release of merozoites from the infected RBC (iRBC) (5). Furthermore, in the case of P. falciparum, the sequestration and destruction of iRBC in the vasculature of lymphoid organs and the brain exacerbates this pathology (6). Disease severity was previously solely attributed to parasite virulence factors (5). However, recent studies have suggested that modulation of the immune system is involved in the development of pathology through the induction of a strong inflammatory response at the beginning of the acute phase, followed by a suppression of the host immune system at later time points (7).

\section{MALARIA AND INFLAMMATION}

Systemic hyperactivation in P. falciparum-infected patients is characterized by elevated levels of circulating nitrogen oxide reactive intermediates $(8,9)$ and by various cytokines, such as IFN $\alpha / \gamma(10$ 12), TNF $\alpha$ (5, 13-18), IL-1 (5), IL-6 (19), and the chemokine IL-8 (20). Furthermore, the levels of these cytokines and chemokines have been found to correlate with different manifestations of severe malaria $(14,16-19)$. Although the generation of these proinflammatory molecules favors reduction of the parasitic load, their exacerbated production seems to play a key role in the development of pathology. Both TNF $\alpha$ and IL-1 $\beta$ are considered to be important mediators of fever (3), and participate in the attachment of P. falciparum-iRBC to the vascular endothelium (21-23). And in vivo studies have demonstrated that the cytokines TNF $\alpha$ and IFN $\gamma$ are essential for the development of cerebral malaria by inducing the expression of the adhesion molecule ICAM-1 and nitric oxide (NO) $(24,25)$. Finally, an in vitro study has shown that the induction of the pyrogenic molecules MIP- $1 \alpha$ and MIP$1 \beta$ by Plasmodium may play an important role in the initiation of fever (26).

During human or murine malaria, phagocytes [e.g., monocytes/macrophages (MØ), and to a lesser extent neutrophils $(\mathrm{N} \varnothing)]$ have been demonstrated to play a crucial role in host defense by engulfing free parasites and Plasmodium-iRBC, and 
by eliminating parasites through a respiratory burst-mediated mechanism $(27,28)$. During the early phase of the infection, the number of phagocytes increases and their activity intensifies (29-33). Moreover, since tissue and circulating $M \varnothing$ are the main source of cytokines during severe malaria (5), it seems that their contribution to the exacerbation of the inflammatory response is also important. For instance, in vitro studies have reported the production of several phagocyte-secreted molecules (e.g., IL-1, IL-6, IL-12, and TNF $\alpha)(3,5,14,15,34-40)$ by human and murine $\mathrm{M} \varnothing$ upon contact with Plasmodium-iRBC or malarial antigens. Furthermore, the enhanced IFN $\gamma$ production (19, 41), complement activation (42), and hypergammaglobulinemia observed during the course of acute malarial infection could stimulate cytokine release by $\mathrm{M} \varnothing(43,44)$. Additionally, the production of leukotrienes and reactive oxygen species (ROS) by phagocytes during infection seems to contribute to malaria pathogenesis (5).

\section{HZ AND MALARIA}

Although enhanced activation of the immune system has been reported during the early stage of the malarial infection, a markedly reduced or absent immune response is observed later during the acute phase of human and murine malaria $(45,46)$. The most well-studied mechanism explaining this phenomenon is the reduction of $T$ cell proliferation and activity that occurs during malarial infection $(47,48)$. However, the reduction in T cell numbers is transient (49), and the restoration of their basal numbers does not restore their ability to specifically respond to malaria antigens (29), suggesting that other components of the immune system are also affected. Accordingly, various models of murine malaria have demonstrated that $\mathrm{M} \varnothing$ functions (e.g., antigen presentation and microbicidal functions) $(7,10,29,50-54)$ are greatly altered during the course of infection, but the mechanisms involved in the functional modulation of $\mathrm{M} \varnothing$ by Plasmodium are still incompletely understood. Several lines of evidence suggest that the parasite and its metabolites, principally hemozoin (HZ) and glycosylphosphatidylinositol (GPI), which are released into circulation during the intraerythrocytic cycle, could contribute to the activation and/or the suppression of the immune response $(7,52,55$, 56). The impact of $\mathrm{HZ}$ on host physiology and the host response has been a subject of increasingly intensive studies over the last 10 years, and already published data suggest that this metabolite could have an important role in malaria pathophysiology.

Hemozoin is a crystalline, brown pigment that is formed and sequestered in the digestive vacuole of Plasmodium as a product of hemoglobin $(\mathrm{Hb})$ catabolism (57). The parasite digests up to $80 \%$ of the $\mathrm{Hb}$ in the host $\mathrm{RBC}$, which it utilizes as an essential source of nutrients and energy (2). However, this process generates heme, which is highly toxic to the parasites. Since the parasite is unable to excrete the free heme and does not possess a heme oxygenase to recover the iron and detoxify the heme, it aggregates the heme into an insoluble crystal, $\operatorname{HZ}(58,59)$. It was initially thought that this reaction was conducted by a heme polymerase (60). Some proteins have been proposed as candidates (61), but HZ formation does not require the use of a protein or a lipid (62-65), thus this aspect of $\mathrm{HZ}$ metabolism remains controversial (61).

In vivo, $\mathrm{HZ}$ crystals are remarkably uniform in size and shape; however, only certain synthetic protocols allow for the isolation of synthetic crystals with this morphology $(58,66,67)$, with many synthetic protocols yielding material that is poorly crystalline (58, 68). HZ is composed of hematin molecules bonded by reciprocal iron-carboxylate linkages to form dimers, which are further connected via hydrogen bonds to form a triclinic crystal (69-71). Although HZ is remarkably thermally stable and insoluble, it has one of the highest concentrations of pro-oxidant sites of any condensed biomaterial, and therefore it may be the source of slowly released oxidation catalysts or the site of surface generated oxidation catalysts. Electron diffraction has been used to index the faces of $\mathrm{HZ}$ to determine the specific structures on each surface. The smallest, fastest growing faces are dominated by free propionic acid groups, while the larger faces of the crystal correspond to the hydrophobic flat porphyrin plane of the hematin dimers. Thus, these two pairs of faces on the HZ prisms contrast markedly in nature, with the former being very polar and hydrophilic, and the latter being hydrophobic and lipophilic.

In the past, $\mathrm{HZ}$ was only considered to be a metabolic waste, i.e., merely the byproduct of heme detoxification by the parasite (56). However, this molecule has been shown to sequester in various organs (e.g., liver, spleen, and brain), to be actively engulfed by phagocytes, and to modulate $\mathrm{M} \varnothing$ functions, indicating that $\mathrm{HZ}$ can potentially contribute to the development of malaria immunopathogenesis $(2,26,72-80)$. Following the rupture of Plasmodium-iRBC, HZ is released from the parasite digestive vacuole and is rapidly engulfed by phagocytes $(29,33,56)$. In human and murine malaria, a large number of circulating phagocytes are loaded with HZ, as are phagocytes in the brain and lymphoid organs, such as the spleen $(26,29,30,56,58,81)$, where its presence seems to correlate with the severity of the disease. Although HZ is generated during malarial infection caused by all Plasmodium species, including the species-infecting mice (e.g., P. chabaudi and $P$. berghei), the amount released during severe or cerebral malarial infection due to $P$. falciparum, can be markedly more abundant and localized than compared to mild cases of malaria observed in individuals infected with P. malariae, P. ovale, or P. vivax (82).

\section{HZ, IMMUNE CELLS, AND INFLAMMATION}

Hemozoin accumulation occurs during erythrocyte rupture: merozoites, along with $\mathrm{HZ}$, free heme, and other contents of the cytoplasm and digestive vacuole of the parasite are released. Many immune cells such as monocytes, macrophages, neutrophils, endothelial cells, and dendritic cells are able to interact with and internalize $\mathrm{HZ}$ and iRBC. Among these, the most well-characterized HZ-internalizing cells are the monocytes and macrophages. It has been well documented that human monocytes rapidly engulf $\mathrm{HZ}$, which can fill up to $30 \%$ of their total cell volume. Furthermore, the consumed $\mathrm{HZ}$ can persist unmodified within the monocytes for long periods of time (83).

Accumulation of $\mathrm{HZ}$ in the phagocytic cells of the immune system is used in the diagnosis and prognosis of malaria. In pioneering studies, Laveran described the presence of the pigment granules not only in the $\mathrm{iRBC}$, but also in phagocytes; in some cases, $\mathrm{HZ}$ could be detected in RBC that did not contain parasites (84). High levels of HZ within monocytes and neutrophils have been shown to correlate with disease severity. It was observed that adult patients who succumbed to $P$. falciparum 


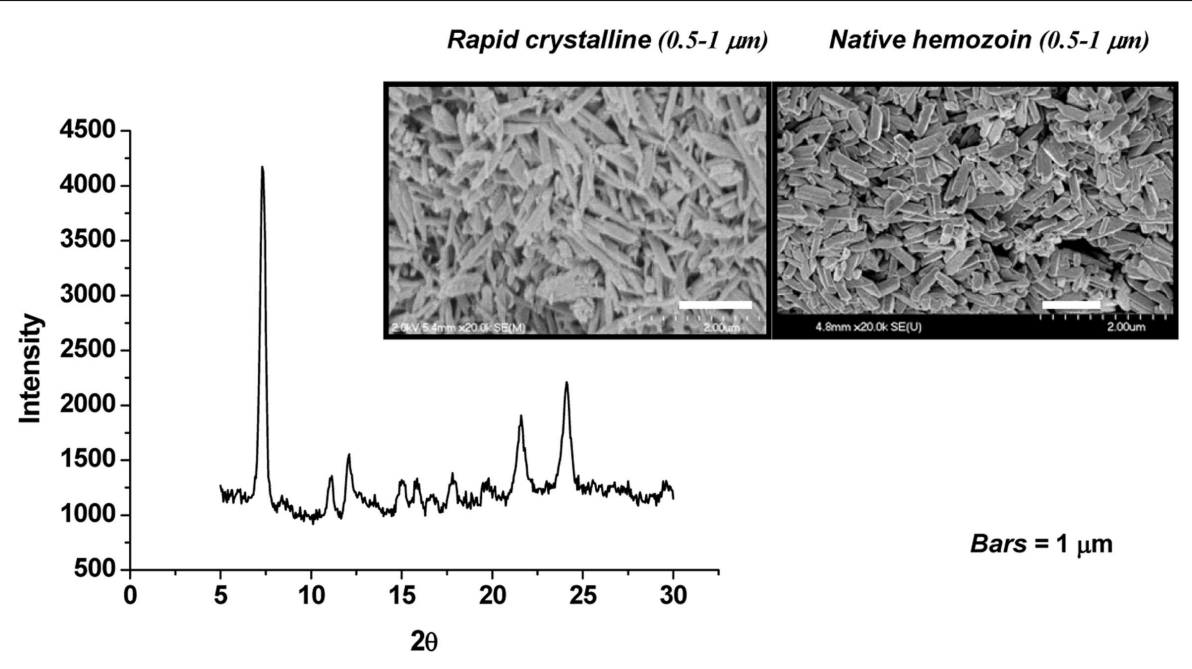

FIGURE 1 | Synthetic hemozoin analysis. Scanning electron micrographs of rapid crystalline HZ (rcHZ) and Plasmodium falciparum-native HZ. X-ray powder diffraction (XRD) analysis allows the determination of the quality of the crystal. Taken from Ref. (86).

infections presented with a higher proportion of HZ-containing neutrophils or monocytes than surviving patients (75). Additionally, it has been shown that children with cerebral malaria have more HZ-containing neutrophils than mildly infected or asymptomatic children (82). Furthermore, patients with severe malaria have iRBC and HZ-laden monocytes in their brain capillaries (85). The same profile of $\mathrm{HZ}$ accumulation within the organs has also been observed in the murine model of cerebral malaria (80). The presence of HZ in these immune cells corresponds with its immune modulatory activity.

The role of $\mathrm{HZ}$ in the modulation of host innate and inflammatory responses has been investigated by many researchers, using different $\mathrm{HZ}$ preparation protocols. $\mathrm{HZ}$ can be synthesized from hematin (sHZ) or native hemozoin $(\mathrm{nHZ})$ can be purified from iRBC in culture (Figure 1). $\mathrm{nHZ}$ needs to be further treated to remove any proteins, lipids, and other materials from disrupted parasite that could have adhered to the highly amphiphilic molecule, in order to obtain a pure product. These HZ preparations have been used to gain a greater and more thorough understanding of the role of $\mathrm{HZ}$ in malarial pathology. Although sHZ and nHZ crystals of similar sizes are capable of inducing the same level of inflammatory mediators, $\mathrm{sHZ}$ with a smaller or larger crystal size will differently affect the production of pro-inflammatory cytokines. This is believed to occur because the smaller crystal sizes have a greater surface of interaction for a given amount of material (86).

Over the last 10-15 years, several groups have reported that $\mathrm{HZ}$ accumulation within $\mathrm{M} \varnothing$ modulates several of their functions, and is associated with some malarial symptoms, such as fever, anemia, and splenomegaly $(26,88)$. It has been determined that human monocytes and murine $\mathrm{M} \varnothing$ stimulated with $\mathrm{HZ}$ (purified from various species of Plasmodium or synthetically generated) produce large amounts of cytokines (IL-10, IL-12, IL-1 $\beta$, and TNF $\alpha$ ), chemokines (MIP-1 $\alpha$ and MIP-1 $\beta$ ), MIF erythropoietic inhibitor, and adhesion molecules (CD11/CD18) (4, 26, 45, 89). Consistent with these observations, we previously published the first report that in vivo inoculation of sHZ rapidly induces the generation of various pro-inflammatory mediators, including myeloid-related proteins (MRPs; S100A8 and S100A9), chemokines (MIP-1 $\alpha / \beta$, MIP-2, and MCP-1), and cytokines (90); strongly suggesting that $\mathrm{HZ}$ itself might play an important role in the development of malaria-related pathologies. Additionally, in vitro studies from our laboratory revealed that $\mathrm{HZ}$ significantly enhances IFN $\gamma$-induced NO production by MØ (91), an important inflammatory event that could favor cerebral malaria development. We also found that native $P f H Z$ - and sHZ-induced $\mathrm{M} \varnothing$ chemokine expression is regulated by oxidative stress-dependent (92) and -independent mechanisms. Contrastingly, some in vitro studies have shown that $\mathrm{M} \varnothing$ which have internalized $\mathrm{HZ}$ for a long period of time (over $24 \mathrm{~h}$ ), exhibited inhibition of PKC (68) and NADPH oxidase (72), IFN $\gamma$-inducible class II (MHC-II) expression (45), LPS-induced functions (e.g., CD14, and TNF $\alpha)(34,79,93,94)$, phagocytosis (72), microbicidal activity (74), and the respiratory burst (95). Despite these functional alterations and the possible toxic effects of oxygen radicals and lipoperoxidation triggered following $\mathrm{HZ}$ phagocytosis $(72,87,88)$, the $\mathrm{M} \varnothing$ and monocytes were able to remain viable for several days.

Many studies have reported that $\mathrm{HZ}$ induces TNF $\alpha$ gene transcription and expression. TNF $\alpha$ production has been shown to correlate with severe malaria, as it is found in higher concentrations in the serum of patients with severe malaria compared to those with mild malaria $(96,97)$. Supporting its importance in inflammatory-related processes, $\mathrm{HZ}$-induced $\mathrm{TNF} \alpha$ production by human monocytes was found to be inhibited by IgM purified from malaria patients, but not from healthy donors (98). Another important cytokine involved in malarial fever is IL-1 $\beta$. HZ was found to induce IL-1 $\beta$ expression in an air pouch model (90), and in the liver when intravenously injected (86). Recently, several studies have reported that HZ induces IL- $1 \beta$ production by activating the inflammasome protein complex (99-101). The cellular and molecular mechanisms underlying the ability of $\mathrm{HZ}$ to activate the NLRP3/inflammasome complex will be further discussed later in 

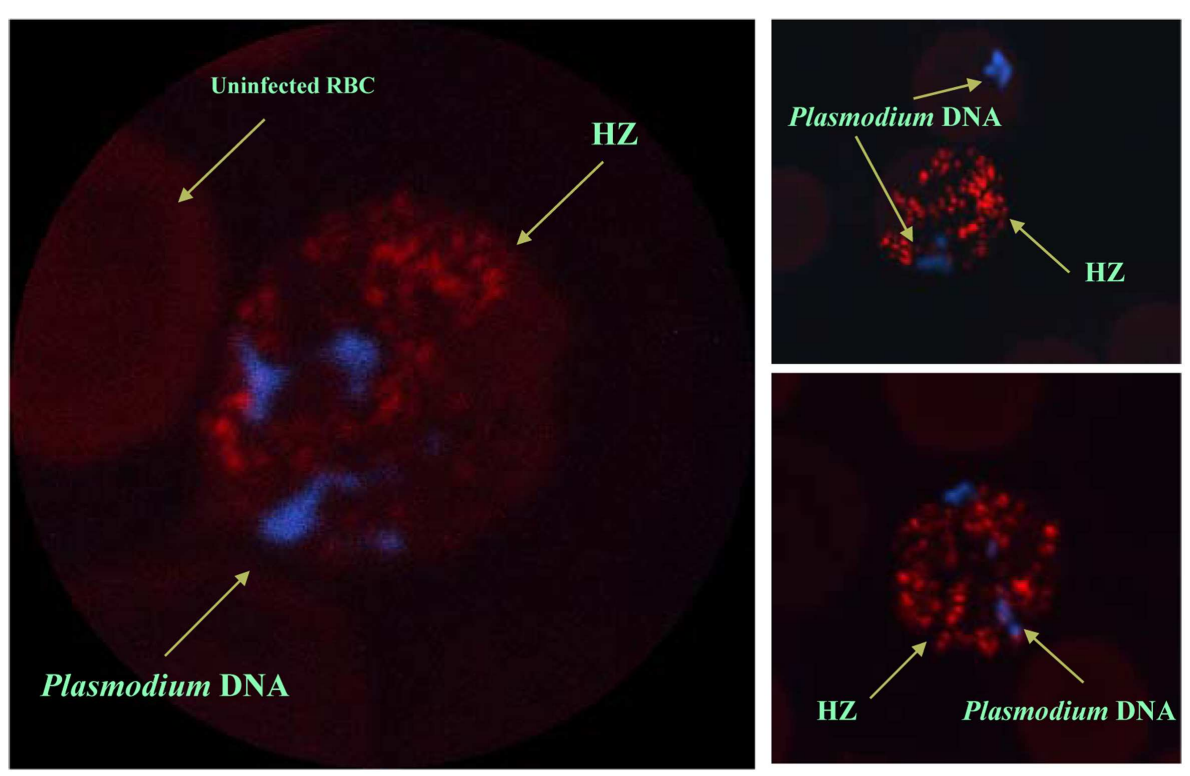

FIGURE 2 | In situ localization of Plasmodium hemozoin and parasitic DNA. Confocal pictures of RBC from Plasmodium chabaudi DK-infected mice. Selected images of schizonts and late trophozoites stages of iRBC. DAPI staining was used to visualize malarial DNA (blue).
No staining was required to localize $\mathrm{HZ}$ since it autofluorescences (red). Even after merozoite release from the iRBC (see top right panel), malarial DNA was never in contact with hemozoin. Images were taken from Ref. (86). this review. Furthermore, it was also found that $\mathrm{HZ}$ can induce the production of IL- 6 by endothelial cells in vitro and that intraperitoneal administration of $\mathrm{HZ}$ can induce IL-6 production in vivo (100). Similar findings were also observed in a more controlled in vivo environment using an air pouch model (90).

Apart from cytokines, $\mathrm{HZ}$ also causes the release of various chemokines and the expression of chemokine receptors, as was briefly mentioned earlier. The engagement of a chemokine with its specific receptor triggers an intracellular signaling cascade that results in chemotactic recruitment of inflammatory cells, leukocyte activation, and antimicrobial effects (102). Using an air pouch model and intravenous injection (90), as well as murine macrophages $(86,103)$, it was shown that HZ induced the expression of various chemokines (MIP-1 $\alpha /$ CCL3, MIP-1 $\beta / C C L 4$, MIP2/CXCL2, and MCP-1/CCL2) and chemokine receptors (CCR1, CCR2, CCR5, CXCR2, and CXCR4). HZ was also found to augment the production of several $\beta$-chemokines in peripheral blood mononuclear cells (PBMC) (104), endothelial cells (100), and in vivo $(26,105)$. These results strongly support the role of $\mathrm{HZ}$ as a potent pro-inflammatory agent that could contribute to the immunopathology of malaria observed in humans and murine malaria.

\section{HZ/PHAGOCYTE INTERACTION: FROM BASIC SIGNALING TO NLRP3 INFLAMMASOME}

As mentioned above, $\mathrm{HZ}$ is capable of activating different cell types resulting in the release of several pro-inflammatory and anti-inflammatory mediators. However, the intracellular mechanisms underlying HZ-induced cellular events are still under investigation. An initial study revealed a synergism between $\mathrm{HZ}$ and IFN $\gamma$ resulting in the induction of NO production. The generation of the microbicidal agent required the activation of extracellular signal-regulated kinase (ERK) 1/2 pathway, but was independent of an IFN $\gamma$-induced activation of the JAK2/STAT1 pathway (91). However, both ERK and JAK2/STAT-1 signaling was found to be necessary to attain maximal NF- $\mathrm{B}$ activation and iNOS promoter-binding capability (91). NF- $\kappa$ B was also shown to be greatly involved in HZ-induced chemokine expression (103). In addition to MAP kinases, HZ has recently been described to be capable of activating spleen tyrosine kinase (Syk), augmenting inflammasome activation and IL- $1 \beta$ production by THP- 1 human monocytic cells and murine macrophages (99). In the same study, it was revealed that kinases downstream of Lyn/Syk, for instance, MAP kinase family members, might be involved in inflammasome activation, since inhibition of ERK, but not p38, decreased IL-1 $\beta$ production.

Despite the fact that $\mathrm{HZ}$ has been shown to be immunologically active in vitro and in vivo, the cellular receptors recognizing $\mathrm{HZ}$ remain elusive. However, the efficiency of HZ-induced signaling and phagocyte function seem to depend on its internalization and lipid raft integrity. It is well known that the cells of the innate immune system recognize pathogen-associated molecular patterns (PAMPs) or damage-associated molecular patterns (DAMPs) by expressing gene-encoded pattern recognition receptors (PRR), such as Toll-like receptors (TLRs), Nod-like receptors (NLRs), c-type lectin, and RIG-like helicases. TLRs can recognize $P$. falciparum GPI anchors (106), but the HZ-induced response is not dependent on TLRs $(86,100,107,108)$. Nevertheless, the ability of TLRs to sense HZ is still a controversial issue. It is important to be fastidious in the interpretation of these results, as the amphiphilic nature of $\mathrm{HZ}$ allows it to bind certain proteins, lipids, and nucleic acids; therefore, any Plasmodium molecules adhering to HZ during 


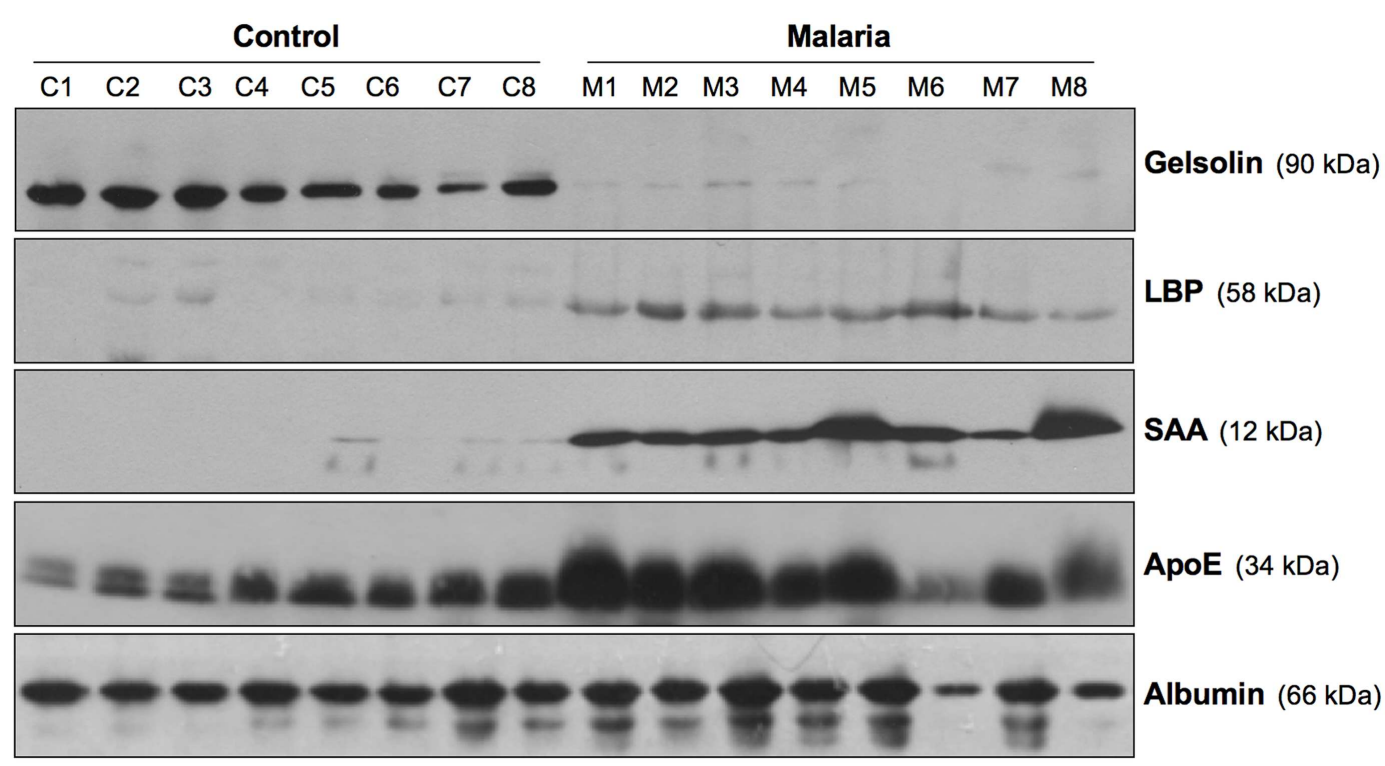

FIGURE 3 | Inflammatory biomarkers adhering to hemozoin. Sera biomarkers from malaria patients and healthy individuals were detected using Western blotting. The membranes were blotted using antibodies specific for gelsolin, LPS-binding protein (LBP), serum amyloid A (SAA), apolipoprotein $E$ (ApoE), and serum albumin. C1-C8, control; M1-M8, malaria. Figure was taken from the supplemental data of Ref. (116). the preparation of nHZ could be sensed by the TLRs. In this context, Parroche et al. (107) proposed that HZ was a carrier of a TLR ligand and that the immune response induced by $\mathrm{HZ}$ was from a possible contamination of $\mathrm{HZ}$ with Plasmodium DNA. However, different research groups have shown that synthetic and native $\mathrm{HZ}$ that are not contaminated by DNA $(86,109)$ are still very powerful immunogenic molecules (83). Furthermore, by using DNA staining and the natural red/green fluorescence of $\mathrm{HZ}$, it was shown that Plasmodium DNA within iRBC never co-localizes with $\mathrm{HZ}$, which is confined to the food vacuole (Figure 2) (86). In this regard, the ability of TLRs to recognize HZ is still unclear, as is the ability of other PRRs to recognize HZ, especially NLRs.

The NLR family of receptors is characterized by three domains: a leucine-rich repeat (LRR) domain in the N-terminus, a central nucleotide-binding domain, and a variable $\mathrm{C}$-terminus. Based on the composition of the C-terminus and central domain, NLRs are divided into different subfamilies: the NLRB subfamily (which consists of one member, NAIP), the NLRC subfamily (NLRC4/IPAF and NOD1, which are NLR containing a CARD domain, and NOD2, which contains two CARD domains); and the NLRP subfamily (NLRP1 and NLRP3, NLR containing a pyrin domain). The members of each subfamily recognize different pathogen-associated molecules; for example: flagellin is recognized by NLRC4, anthrax lethal toxin by NLRP1, muramyl dipeptide and lysin-peptidoglycan by NOD2, meso-diaminopimelic acid-peptidoglycan by NOD1, and a vast spectrum of ligands (bacterial RNA, inorganic materials, gout-associated crystal-MSU, and microbes) by NLRP3. NOD1/NOD2 receptor stimulation has been shown to induce RIP2 kinase-dependent NF- $\kappa$ B activation, resulting in the transcription of pro-inflammatory cytokines (110-112). Recent findings suggest that certain pro-inflammatory events occurring during $P$. berghei ANKA infection may depend on NOD2 (113), however the role of HZ in this circumstance is still incompletely understood. Furthermore, several laboratories have made observations indicating that the NLRP3 inflammasome complex could be involved in a HZ-induced response.

The potential role of the NLRP3 inflammasome in HZtriggered inflammatory events is of particular interest, because IL- $1 \beta$ is known to be integral to the fever episodes and proinflammatory processes observed during Plasmodium infection. However, the results regarding the participation of the inflammasome complex have been slightly inconsistent. Studies by our laboratory (99) and by Dostert et al. (101) showed that HZ-induced IL- $1 \beta$ production and neutrophil recruitment were dependent on the NLRP3 inflammasome. In partial agreement, Griffith et al. (100) showed that HZ-stimulated neutrophil recruitment into the mouse peritoneal cavity was dependent on NLRP3 inflammasome. Additionally, using a murine model, three different studies have demonstrated that NLRP3-deficient mice showed some level of protection against two different murine parasites, $P$. berghei ANKA and P. chabaudi adami DS $(99,101,114)$. Nevertheless, this protection cannot be solely attributed to $\mathrm{HZ}$, as during the course of Plasmodium infection, a number of factors from the pathogen and the host immune system will contribute to the outcome of the infection. Moreover, our study revealed that Plasmodium-infected NLRP3- and IL-1 $\beta$-deficient mice have a lower body temperature compared to wild-type. This finding is consistent with the potential role of $\mathrm{HZ}$ during malarial infection, as it is released during iRBC lysis, which is usually followed by an episode of fever. Furthermore, the laboratory of Scharzwer recently reported that the attachment of fibrinogen to $\mathrm{HZ}$ imbued $\mathrm{HZ}$ with a greater capacity to activate host inflammatory functions (115). In this context, recent data from our laboratory (116) revealed that $\mathrm{HZ}$ interacts with a large number of inflammatory-related biomarkers 


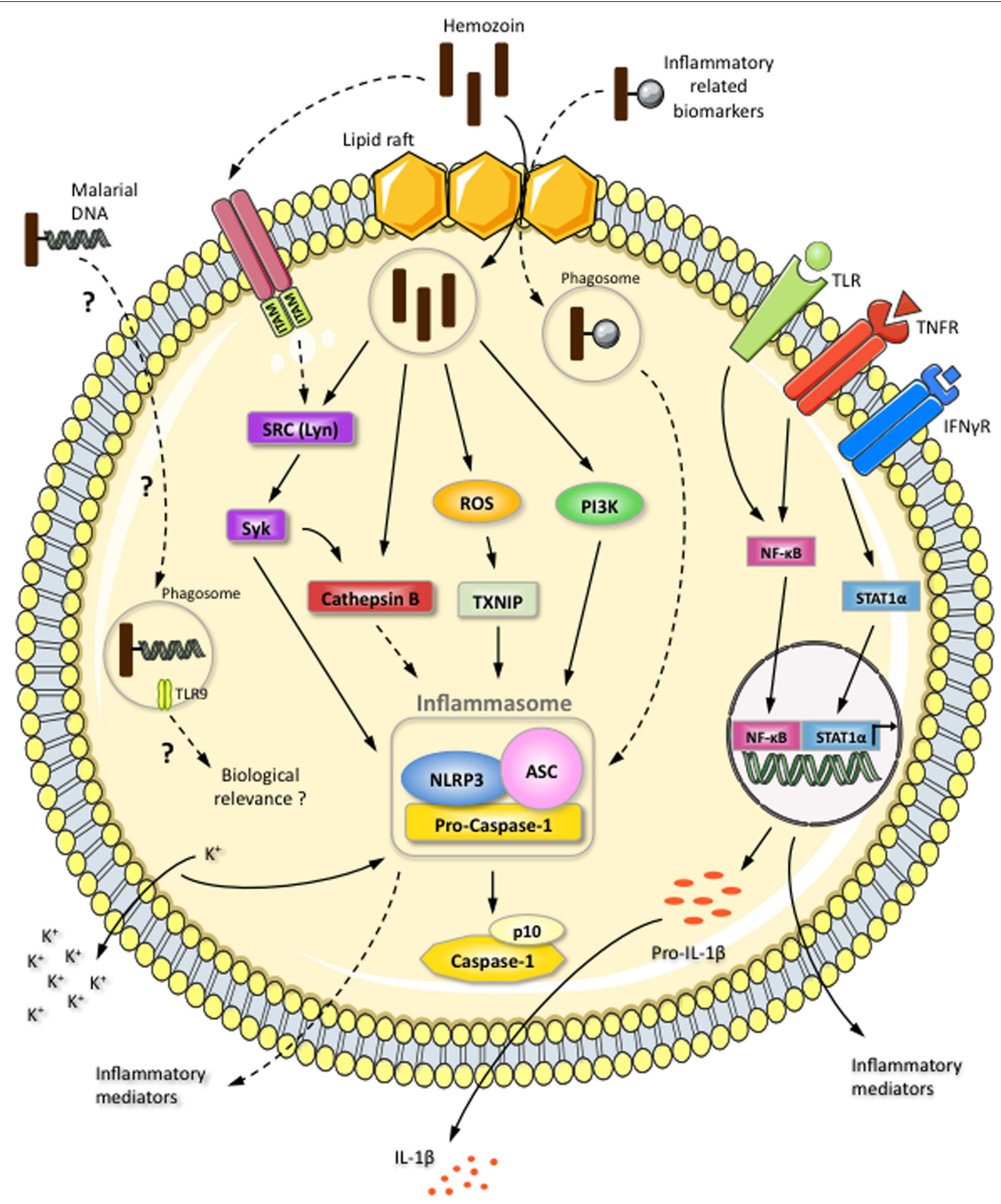

FIGURE 4 | Induction of NLRP3 inflammasome complex by the inorganic crystal HZ. HZ induces IL-1 $\beta$ production via the NLRP3/ASC inflammasome: activation of caspase- 1 results in the cleavage of pro-IL-1 $1 \beta$. Pro-IL-1 $\beta$ expression is resultant of the TLR4- and TNF $\alpha$-activated NF-kB pathway or the IFN $\gamma$-stimulated STAT-1 $\alpha$ pathway. The HZ-activated NLRP3 inflammasome is dependent on potassium efflux, ROS generation, $\mathrm{HZ}$ internalization, and cathepsin $\mathrm{B}$ activation. $\mathrm{HZ}$ internalization and the induction of SRC kinase signaling are mediated by lipid rafts. An ITAM-containing receptor could also be the starting point of SRC kinase cascade. $\mathrm{HZ}$ is internalized within a phagosome-like vesicle surrounded by LAMP-1. HZ activation of the SRC kinase Lyn leads to Syk phosphorylation. Subsequently, Syk positively modulates cathepsin $\mathrm{B}$ activation, which could result in the induction of the NLRP3 inflammasome. $\mathrm{HZ}$ is also capable of activating the NLRP3 inflammasome through PI3 kinase. The involvement of malarial DNA, which can adhere to $\mathrm{HZ}$, in the activation of an intracellular receptor and its biological relevance are controversial and only reported for dendritic cells, which are present in limited numbers in the blood. $\mathrm{HZ}$ can interact with a large number of inflammatory-related biomarkers found in the circulation of $P$.

falciparum-infected patients. However, the effect of these biomarkers on NLRP3 inflammasome activation is still unknown. Continuous arrows indicate a positive modulation. Dotted arrows indicate a hypothetical effect. Dotted arrows with a question mark indicate an unknown or controversial effect. 
(e.g., fibrinogen, serum amyloid A (SAA), LPS-binding protein (LBP), and apolipoproteins) found in the circulation of P. falciparum-infected patients (Figure 3). The potential of these molecules to modify the interaction of $\mathrm{HZ}$ with immune cells is of great interest, as it could exacerbate the inflammatory events occurring during malaria.

The mechanisms underlying the activation of the NLRP3/ inflammasome complex by HZ are currently under investigation. Three models have been proposed: potassium channel efflux, lysosome rupture, and/or ROS generation (117) (Figure 4). Two independent groups have illustrated the involvement of potassium efflux, phagocytosis, and ROS generation in inflammasome activation $(99,101)$. However, there is a discrepancy in whether cathepsin B is involved, depending on the approach used. Cathepsin B-deficient mice showed no effect (101), whereas cathepsin B-specific inhibitors were found to block inflammasome activation (99). Nevertheless, HZ-triggered inflammasome activation seems to involve at least two of the proposed models (potassium channel efflux and ROS generation) and cathepsin B activation. Disruption of the phagolysosome by $\mathrm{HZ}$ does not appear to occur, since $\mathrm{HZ}$ has been shown to be contained in vacuoles surrounded by LAMP-1, and cathepsin B has not been found in culture supernatant, which is generally the case for asbestos and silica (99), which not only disrupt the phagolysosome, but also kill the phagocytic cells. Of utmost importance, our study revealed that Lyn/Syk kinases are the upstream signaling partners in the activation of the NLRP3/inflammasome complex (Figure 4). The participation of these kinases in $\mathrm{HZ}$-induced inflammasome activation is highly suggestive that an ITAM-containing receptor on the surface of the host cell could be the starting point for this biochemical cascade. However, it is also possible that HZ is capable of modulating the lipid raft environment, which could initiate the signaling cascade (Figure 4).

Finally, it is important to stress that inorganic crystals like asbestos, silica, and MSU not only disrupt phagolysosome integrity, but are also highly apoptotic and disruptive to cell integrity. Conversely, $\mathrm{HZ}$ is able to stay within host cells for long periods of time, from several days to weeks, without discernably affecting phagocyte viability (118). Moreover, HZ is markedly smaller than the other inorganic crystals mentioned above and is fully engulfed by the host cells, unlike the other crystals mentioned.

In conclusion, it is has been established that $\mathrm{HZ}$ is a powerful modulator of the innate immune response, which suggests that it has the potential to be detrimental or beneficial to the host depending on the stage of the infection. Furthermore, it has recently been demonstrated that $\mathrm{HZ}$ is sensed as a danger signal, resulting in the activation of the inflammasome $(99,101)$. However, there are contradicting results regarding the modulation of the immune response by $\mathrm{HZ}$. These differences can be explained at least in part by the different cell types and incubation times used in various studies, and most prominently, by the quality of the HZ crystal utilized. Therefore, a unified method to generate sHZ crystals, which more closely resembles the ones naturally produced by Plasmodium, needs to be established. Additionally, ensuring that the resulting $\mathrm{sHZ}$ crystals possess the correct quality, size, and crystallinity by using X-ray powder diffraction (XRD) analysis would aid in attaining more reproducible data.

\section{ACKNOWLEDGMENTS}

Research in the Martin Olivier laboratory is supported by operating grants from the Canadian Institute of Health Research. Martin Olivier is a member of the FQRNT network for the study of host-parasite interaction. Sophie Fougeray is the recipient of a postdoctoral award (Young Researcher Prize) from the Bettencourt Schueller Foundation. Fikregabrail Aberra Kassa is the recipient of an internal studentship from the Faculty of Medicine and the Research Institute of the McGill University Health Centre.

\section{REFERENCES}

1. WHO. World Malaria Report (2009). Available from: http://www.who.int/ malaria/world_malaria_report_2009/en/index.html

2. Francis SE, Sullivan DJ Jr, Goldberg DE. Hemoglobin metabolism in the malaria parasite Plasmodium falciparum. Аnnu Rev Microbiol (1997) 51:97-123. doi: 10.1146/annurev.micro.51.1.97

3. Martiney JA, Sherry B, Metz CN, Espinoza M, Ferrer AS, Calandra T, et al. Macrophage migration inhibitory factor release by macrophages after ingestion of Plasmodium chabaudi-infected erythrocytes: possible role in the pathogenesis of malarial anemia. Infect Immun (2000) 68:2259-67. doi:10.1128/IAI. 68.4.2259-2267.2000

4. Mordmuller B, Turrini F, Long H, Kremsner PG, Arese P. Neutrophils and monocytes from subjects with the Mediterranean G6PD variant: effect of Plasmodium falciparum hemozoin on G6PD activity, oxidative burst and cytokine production. Eur Cytokine Netw (1998) 9:239-45.

5. Urquhart AD. Putative pathophysiological interactions of cytokines and phagocytic cells in severe human falciparum malaria. Clin Infect Dis (1994) 19:117-31. doi:10.1093/clinids/19.1.117

6. Miller LH, Good MF, Milon G. Malaria pathogenesis. Science (1994) 264:1878-83. doi:10.1126/science.8009217

7. Weidanz WP. Malaria and alterations in immune reactivity. Br Med Bull (1982) 38:167-72.

8. Nussler AK, Eling W, Kremsher PG. Patients with Plasmodium falciparum malaria and Plasmodium vivax malaria show increased nitrite and nitrate plasma levels. J Infect Dis (1994) 169:1418-9. doi:10.1093/infdis/169.6.1418

9. Kremsner PG, Winkler S, Wildling E, Prada J, Bienzle U, Graninger W, et al. High plasma levels of nitrogen oxides are associated with severe disease and correlate with rapid parasitological and clinical cure in Plasmodium falciparum malaria. Trans R Soc Trop Med Hyg (1996) 90:44-7. doi:10.1016/S00359203(96)90476-9

10. Brown AE, Webster HK, Teja-Isavadharm P, Keeratithakul D. Macrophage activation in falciparum malaria as measured by neopterin and interferon-gamma. Clin Exp Immunol (1990) 82:97-101. doi:10.1111/j.1365-2249.1990.tb05410.x

11. McCall MB, Sauerwein RW. Interferon-gamma - central mediator of protective immune responses against the pre-erythrocytic and blood stage of malaria. J Leukoc Biol (2010) 88:1131-43. doi:10.1189/jlb.0310137

12. Rhodes-Feuillette A, Bellosguardo M, Druilhe P, Ballet JJ, Chousterman S, Canivet $\mathrm{M}$, et al. The interferon compartment of the immune response in human malaria: II. Presence of serum-interferon gamma following the acute attack. J Interferon Res (1985) 5:169-78. doi:10.1089/jir.1985.5.159

13. Kwiatkowski D, Hill AV, Sambou I, Twumasi P, Castracane J, Manogue KR, et al. TNF concentration in fatal cerebral, non-fatal cerebral, and uncomplicated Plasmodium falciparum malaria. Lancet (1990) 336:1201-4. doi:10.1016/ 0140-6736(90)92827-5

14. Kwiatkowski D, Cannon JG, Manogue KR, Cerami A, Dinarello CA, Greenwood BM. Tumour necrosis factor production in falciparum malaria and its association with schizont rupture. Clin Exp Immunol (1989) 77:361-6.

15. Jakobsen PH, Moon R, Ridley RG, Bate CA, Taverne J, Hansen MB, et al. Tumour necrosis factor and interleukin- 6 production induced by components associated with merozoite proteins of Plasmodium falciparum. Parasite Immunol (1993) 15:229-37. doi:10.1111/j.1365-3024.1993.tb00605.x

16. Grau GE, Taylor TE, Molyneux ME, Wirima JJ, Vassalli P, Hommel M, et al. Tumor necrosis factor and disease severity in children with falciparum malaria. N Engl J Med (1989) 320:1586-91. doi:10.1056/NEJM198906153202404

17. Shaffer N, Grau GE, Hedberg K, Davachi F, Lyamba B, Hightower AW, et al. Tumor necrosis factor and severe malaria. J Infect Dis (1991) 163:96-101. doi:10.1093/infdis/163.1.96 
18. Butcher GA, Garland T, Ajdukiewicz AB, Clark IA. Serum tumor necrosis factor associated with malaria in patients in the Solomon Islands. Trans $R$ Soc Trop Med Hyg (1990) 84:658-61. doi:10.1016/0035-9203(90)90134-Z

19. Kern P, Hemmer CJ, Van Damme J, Gruss HJ, Dietrich M. Elevated tumor necrosis factor alpha and interleukin-6 serum levels as markers for complicated Plasmodium falciparum malaria. Am J Med (1989) 87:139-43. doi:10. 1016/S0002-9343(89)80688-6

20. Friedland JS, Ho M, Remick DG, Bunnag D, White NJ, Griffin GE. Interleukin8 and Plasmodium falciparum malaria in Thailand. Trans $\mathrm{R}$ Soc Trop Med Hyg (1993) 87:54-5. doi:10.1016/0035-9203(93)90417-O

21. Pober JS, Bevilacqua MP, Mendrick DL, Lapierre LA, Fiers W, Gimbrone MA Jr. Two distinct monokines, interleukin 1 and tumor necrosis factor, each independently induce biosynthesis and transient expression of the same antigen on the surface of cultured human vascular endothelial cells. J Immunol (1986) 136:1680-7.

22. Pober JS, Gimbrone MA Jr, Lapierre LA, Mendrick DL, Fiers W, Rothlein R, et al. Overlapping patterns of activation of human endothelial cells by interleukin 1, tumor necrosis factor, and immune interferon. J Immunol (1986) 137:1893-6.

23. Gamble JR, Harlan JM, Klebanoff SJ, Vadas MA. Stimulation of the adherence of neutrophils to umbilical vein endothelium by human recombinant tumor necrosis factor. Proc Natl Acad Sci U S A (1985) 82:8667-71. doi:10.1073/pnas.82.24.8667

24. Rudin W, Eugster HP, Bordmann G, Bonato J, Muller M, Yamage M, et al. Resistance to cerebral malaria in tumor necrosis factor-alpha/betadeficient mice is associated with a reduction of intercellular adhesion molecule1 up-regulation and T helper type 1 response. Am J Pathol (1997) 150:257-66.

25. Rudin W, Favre N, Bordmann G, Ryffel B. Interferon-gamma is essential for the development of cerebral malaria. Eur J Immunol (1997) 27:810-5. doi:10.1002/eji.1830270403

26. Sherry BA, Alava G, Tracey KJ, Martiney J, Cerami A, Slater AF. Malaria-specific metabolite hemozoin mediates the release of several potent endogenous pyrogens (TNF, MIP-1 alpha, and MIP-1 beta) in vitro, and altered thermoregulation in vivo. J Inflamm (1995) 45:85-96.

27. Wozencraft AO, Croft SL, Sayers G. Oxygen radical release by adherent cell populations during the initial stages of a lethal rodent malarial infection. Immunology (1985) 56:523-31.

28. Dockrell HM, Alavi A, Playfair JH. Changes in oxidative burst capacity during murine malaria and the effect of vaccination. Clin Exp Immunol (1986) 66:37-43.

29. Ho M, Webster HK. Immunology of human malaria. A cellular perspective. Parasite Immunol (1989) 11:105-16. doi:10.1111/j.1365-3024.1989.tb00652.x

30. Facer CA, Brown J. Monocyte erythrophagocytosis in falciparum malaria. Lancet (1981) 1:897-8. doi:10.1016/S0140-6736(81)92172-3

31. Vernes A. Phagocytosis of $P$. falciparum parasitised erythrocytes by peripheral monocytes. Lancet (1980) 2:1297-8. doi:10.1016/S0140-6736(80)92357-0

32. Sun T, Chakrabarti C. Schizonts, merozoites, and phagocytosis in falciparum malaria. Ann Clin Lab Sci (1985) 15:465-9.

33. Celada A, Cruchaud A, Perrin LH. Phagocytosis of Plasmodium falciparumparasitized erythrocytes by human polymorphonuclear leukocytes. J Parasitol (1983) 69:49-53. doi:10.2307/3281273

34. Prada J, Prager C, Neifer S, Bienzle U, Kremsner PG. Production of interleukin6 by human and murine mononuclear leukocytes stimulated with Plasmodium antigens is enhanced by pentoxifylline, and tumor necrosis factor secretion is reduced. Infect Immun (1993) 61:2737-40.

35. Sam H, Stevenson MM. Early IL-12 p70, but not p40, production by splenic macrophages correlates with host resistance to blood-stage Plasmodium chabaudi AS malaria. Clin Exp Immunol (1999) 117:343-9. doi:10.1046/j. 1365-2249.1999.00966.x

36. Stoiser B, Looareesuwan S, Thalhammer F, Daxbock F, Chullawichit S, ElMenyawi I, et al. Serum concentrations of granulocyte-colony stimulating factor in complicated Plasmodium falciparum malaria. Eur Cytokine Netw (2000) 11:75-80.

37. Taverne J, Bate CA, Kwiatkowski D, Jakobsen PH, Playfair JH. Two soluble antigens of Plasmodium falciparum induce tumor necrosis factor release from macrophages. Infect Immun (1990) 58:2923-8.

38. Taverne J, Bate CA, Sarkar DA, Meager A, Rook GA, Playfair JH. Human and murine macrophages produce TNF in response to soluble antigens of
Plasmodium falciparum. Parasite Immunol (1990) 12:33-43. doi:10.1111/j. 1365-3024.1990.tb00934.x

39. Picot S, Peyron F, Vuillez JP, Barbe G, Marsh K, Ambroise-Thomas P. Tumor necrosis factor production by human macrophages stimulated in vitro by Plasmodium falciparum. Infect Immun (1990) 58:214-6.

40. Bate CA, Taverne J, Playfair JH. Malarial parasites induce TNF production by macrophages. Immunology (1988) 64:227-31.

41. Ho M, Webster HK. T cell responses in acute falciparum malaria. Immunol Lett (1990) 25:135-8. doi:10.1016/0165-2478(90)90105-Y

42. Greenwood BM, Brueton MJ. Complement activation in children with acute malaria. Clin Exp Immunol (1974) 18:267-72.

43. Okusawa S, Dinarello CA, Yancey KB, Endres S, Lawley TJ, Frank MM, et al. C5a induction of human interleukin 1. Synergistic effect with endotoxin or interferon-gamma. J Immunol (1987) 139:2635-40.

44. Goodman MG, Chenoweth DE, Weigle WO. Induction of interleukin 1 secretion and enhancement of humoral immunity by binding of human C5a to macrophage surface C5a receptors. J Exp Med (1982) 156:912-7. doi:10.1084/jem.156.3.912

45. Schwarzer E, Alessio M, Ulliers D, Arese P. Phagocytosis of the malarial pigment, hemozoin, impairs expression of major histocompatibility complex class II antigen, CD54, and CD11c in human monocytes. Infect Immun (1998) 66:1601-6.

46. Zuckerman A. Current status of the immunology of blood and tissue protozoa: II. Plasmodium. Exp Parasitol (1977) 42:374-446. doi:10.1016/0014-4894(77) 90095-9

47. Greenwood BM, Bradley-Moore AM, Bryceson AD, Palit A. Immunosuppression in children with malaria. Lancet (1972) 1:169-72. doi:10.1016/S01406736(72)90569-7

48. Troye-Blomberg M, Romero P, Patarroyo ME, Bjorkman A, Perlmann P. Regulation of the immune response in Plasmodium falciparum malaria. III. Proliferative response to antigen in vitro and subset composition of $\mathrm{T}$ cells from patients with acute infection or from immune donors. Clin Exp Immunol (1984) 58:380-7.

49. Ho M, Webster HK, Looareesuwan S, Supanaranond W, Phillips RE, Chanthavanich $\mathrm{P}$, et al. Antigen-specific immunosuppression in human malaria due to Plasmodium falciparum. J Infect Dis (1986) 153:763-71. doi:10.1093/infdis/ 153.4.763

50. Ho M, White NJ, Looareesuwan S, Wattanagoon Y, Lee SH, Walport MJ, et al. Splenic Fc receptor function in host defense and anemia in acute Plasmodium falciparum malaria. J Infect Dis (1990) 161:555-61. doi:10.1093/infdis/161.3. 555

51. Warren HS, Weidanz WP. Malarial immunodepression in vitro: adherent spleen cells are functionally defective as accessory cells in the response to horse erythrocytes. Eur J Immunol (1976) 6:816-9. doi:10.1002/eji.1830061112

52. Murphy JR. Host defenses in murine malaria: nonspecific resistance to Plasmodium berghei generated in response to Mycobacterium bovis infection or Corynebacterium parvum stimulation. Infect Immun (1981) 33: 199-211.

53. Murphy JR, Lefford MJ. Host defenses in murine malaria: evaluation of the mechanisms of immunity to Plasmodium yoelii infection. Infect Immun (1979) 23:384-91.

54. Loose LD, Trejo R, Di Luzio NR. Impaired endotoxin detoxification as a factor in enhanced endotoxin sensitivity of malaria infected mice. Proc Soc Exp Biol Med (1971) 137:794-7. doi:10.3181/00379727-137-35669

55. Clark IA, Virelizier JL, Carswell EA, Wood PR. Possible importance of macrophage-derived mediators in acute malaria. Infect Immun (1981) 32:1058-66.

56. Arese P, Schwarzer E. Malarial pigment (haemozoin): a very active 'inert' substance. Ann Trop Med Parasitol (1997) 91:501-16. doi:10.1080/ 00034989760879

57. Pandey AV, Tekwani BL. Formation of haemozoin/beta-haematin under physiological conditions is not spontaneous. FEBS Lett (1996) 393:189-93. doi:10. 1016/0014-5793(96)00881-2

58. Slater AF, Swiggard WJ, Orton BR, Flitter WD, Goldberg DE, Cerami A, et al. An iron-carboxylate bond links the heme units of malaria pigment. Proc Natl Acad Sci U S A (1991) 88:325-9. doi:10.1073/pnas.88.2.325

59. Slater AF. Malaria pigment. Exp Parasitol (1992) 74:362-5. doi:10.1016/00144894(92)90162-4 
60. Slater AF, Cerami A. Inhibition by chloroquine of a novel haem polymerase enzyme activity in malaria trophozoites. Nature (1992) 355:167-9. doi:10.1038/355167a0

61. Lynn A, Chandra S, Malhotra P, Chauhan VS. Heme binding and polymerization by Plasmodium falciparum histidine rich protein II: influence of $\mathrm{pH}$ on activity and conformation. FEBS Lett (1999) 459:267-71. doi:10.1016/S00145793(99)01260-0

62. Dorn A, Stoffel R, Matile H, Bubendorf A, Ridley RG. Malarial haemozoin/betahaematin supports haem polymerization in the absence of protein. Nature (1995) 374:269-71. doi:10.1038/374269a0

63. Bendrat K, Berger BJ, Cerami A. Haem polymerization in malaria. Nature (1995) 378:138-9. doi:10.1038/378138a0

64. Ridley RG. Haemozoin formation in malaria parasites: is there a haem polymerase? Trends Microbiol (1996) 4:253-4. doi:10.1016/0966-842X(96) 30021-8

65. Fitch CD, Cai GZ, Chen YF, Shoemaker JD. Involvement of lipids in ferriprotoporphyrin IX polymerization in malaria. Biochim Biophys Acta (1999) 1454:31-7. doi:10.1016/S0925-4439(99)00017-4

66. Fitch CD, Kanjananggulpan P. The state of ferriprotoporphyrin IX in malaria pigment. J Biol Chem (1987) 262:15552-5.

67. Bohle DS, Kosar AD, Stephens PW. Phase homogeneity and crystal morphology of the malaria pigment beta-hematin. Acta Crystallogr D Biol Crystallogr (2002) 58:1752-6. doi:10.1107/S0907444902014294

68. Schwarzer E, Turrini F, Giribaldi G, Cappadoro M, Arese P. Phagocytosis of $P$. falciparum malarial pigment hemozoin by human monocytes inactivates monocyte protein kinase C. Biochim Biophys Acta (1993) 1181:51-4. doi:10.1016/0925-4439(93)90089-J

69. Pagola S, Stephens PW, Bohle DS, Kosar AD, Madsen SK. The structure of malaria pigment beta-haematin. Nature (2000) 404:307-10. doi:10.1038/ 35005132

70. Klonis N, Dilanian R, Hanssen E, Darmanin C, Streltsov V, Deed S, et al. Hematin-hematin self-association states involved in the formation and reactivity of the malaria parasite pigment, hemozoin. Biochemistry (2010) 49:6804-11. doi:10.1021/bi100567j

71. Gildenhuys J, le Roex T, Egan TJ, de Villiers KA. The single crystal X-ray structure of beta-hematin DMSO solvate grown in the presence of chloroquine, a beta-hematin growth-rate inhibitor. J Am Chem Soc (2013) 135:1037-47. doi:10.1021/ja308741e

72. Schwarzer E, Arese P. Phagocytosis of malarial pigment hemozoin inhibits NADPH-oxidase activity in human monocyte-derived macro phages. Biochim Biophys Acta (1996) 1316:169-75. doi:10.1016/0925-4439(96) 00021-X

73. Pichyangkul S, Saengkrai P, Webster HK. Plasmodium falciparum pigment induces monocytes to release high levels of tumor necrosis factor-alpha and interleukin-1 beta. Am J Trop Med Hyg (1994) 51:430-5.

74. Fiori PL, Rappelli P, Mirkarimi SN, Ginsburg H, Cappuccinelli P, Turrini F. Reduced microbicidal and anti-tumour activities of human monocytes after ingestion of Plasmodium falciparum-infected red blood cells. Parasite Immunol (1993) 15:647-55. doi:10.1111/j.1365-3024.1993.tb00579.x

75. Nguyen PH, Day N, Pram TD, Ferguson DJ, White NJ. Intraleucocytic malaria pigment and prognosis in severe malaria. Trans R Soc Trop Med Hyg (1995) 89:200-4. doi:10.1016/0035-9203(95)90496-4

76. Prada J, Malinowski J, Muller S, Bienzle U, Kremsner PG. Hemozoin differentially modulates the production of interleukin 6 and tumor necrosis factor in murine malaria. Eur Cytokine Netw (1995) 6:109-12.

77. Taramelli D, Basilico N, Pagani E, Grande R, Monti D, Ghione M, et al. The heme moiety of malaria pigment (beta-hematin) mediates the inhibition of nitric oxide and tumor necrosis factor-alpha production by lipopolysaccharidestimulated macrophages. Exp Parasitol (1995) 81:501-11. doi:10.1006/expr. 1995.1143

78. Morakote N, Justus DE. Immunosuppression in malaria: effect of hemozoin produced by Plasmodium berghei and Plasmodium falciparum. Int Arch Allergy Appl Immunol (1988) 86:28-34. doi:10.1159/000234602

79. Pongponratn E, Riganti M, Bunnag D, Harinasuta T. Spleen in falciparum malaria: ultrastructural study. Southeast Asian J Trop Med Public Health (1987) 18:491-501.

80. Sullivan AD, Ittarat I, Meshnick SR. Patterns of haemozoin accumulation in tissue. Parasitology (1996) 112(Pt 3):285-94. doi:10.1017/S003118200006580X

81. Roberts K, Janovy J. Foundations of Parasitology. 6th ed. Boston: McGraw-Hill (1999).
82. Amodu OK, Adeyemo AA, Olumese PE, Gbadegesin RA. Intraleucocytic malaria pigment and clinical severity of malaria in children. Trans $R$ Soc Trop Med Hyg (1998) 92:54-6. doi:10.1016/S0035-9203(98)90952-X

83. Shio MT, Kassa FA, Bellemare MJ, Olivier M. Innate inflammatory response to the malarial pigment hemozoin. Microbes Infect (2010) 12:889-99. doi:10. 1016/j.micinf.2010.07.001

84. Lawrence C. Laveran remembered: malaria haemozoin in leucocytes. Lancet (1999) 353:1852. doi:10.1016/S0140-6736(99)00187-7

85. Newton CR, Taylor TE, Whitten RO. Pathophysiology of fatal falciparum malaria in African children. Am J Trop Med Hyg (1998) 58:673-83.

86. Jaramillo M, Bellemare MJ, Martel C, Shio MT, Contreras AP, Godbout M, et al. Synthetic Plasmodium-like hemozoin activates the immune response: a morphology - function study. PLoS One (2009) 4:e6957. doi:10.1371/journal. pone.0006957

87. Adachi K, Tsutsui H, Kashiwamura S, Seki E, Nakano H, Takeuchi O, et al. Plasmodium berghei infection in mice induces liver injury by an IL-12- and toll-like receptor/myeloid differentiation factor 88-dependent mechanism. J Immunol (2001) 167:5928-34.

88. Prada J, Malinowski J, Muller S, Bienzle U, Kremsner PG. Effects of Plasmodium vinckei hemozoin on the production of oxygen radicals and nitrogen oxides in murine macrophages. Am J Trop Med Hyg (1996) 54:620-4.

89. Awandare GA, Ouma Y, Ouma C, Were T, Otieno R, Keller CC, et al. Role of monocyte-acquired hemozoin in suppression of macrophage migration inhibitory factor in children with severe malarial anemia. Infect Immun (2007) 75:201-10. doi:10.1128/IAI.01327-06

90. Jaramillo M, Plante I, Ouellet N, Vandal K, Tessier PA, Olivier M. Hemozoininducible proinflammatory events in vivo: potential role in malaria infection. J Immunol (2004) 172:3101-10.

91. Jaramillo M, Gowda DC, Radzioch D, Olivier M. Hemozoin increases IFNgamma-inducible macrophage nitric oxide generation through extracellular signal-regulated kinase- and NF-kappa B-dependent pathways. I Immunol (2003) 171:4243-53.

92. Jaramillo M, Olivier M. Hydrogen peroxide induces murine macrophage chemokine gene transcription via extracellular signal-regulated kinase- and cyclic adenosine 5'-monophosphate (cAMP)-dependent pathways: involvement of NF-kappa B, activator protein 1, and cAMP response element binding protein. J Immunol (2002) 169:7026-38.

93. Schwarzer E, Muller O, Arese P, Siems WG, Grune T. Increased levels of 4-hydroxynonenal in human monocytes fed with malarial pigment hemozoin. A possible clue for hemozoin toxicity. FEBS Lett (1996) 388:119-22. doi:10.1016/0014-5793(96)00523-6

94. Pichyangkul S, Yongvanitchit K, Kum-arb U, Hemmi H, Akira S, Krieg AM, et al. Malaria blood stage parasites activate human plasmacytoid dendritic cells and murine dendritic cells through a Toll-like receptor 9-dependent pathway. J Immunol (2004) 172:4926-33.

95. Schwarzer E, Turrini F, Ulliers D, Giribaldi G, Ginsburg H, Arese P. Impairment of macrophage functions after ingestion of Plasmodium falciparum-infected erythrocytes or isolated malarial pigment. J Exp Med (1992) 176:1033-41. doi:10.1084/jem.176.4.1033

96. Keller CC, Yamo O, Ouma C, Ong'echa JM, Ounah D, Hittner JB, et al. Acquisition of hemozoin by monocytes down-regulates interleukin-12 p40 (IL-12p40) transcripts and circulating IL-12p70 through an IL-10-dependent mechanism: in vivo and in vitro findings in severe malarial anemia. Infect Immun (2006) 74:5249-60. doi:10.1128/IAI.00843-06

97. Luty AJ, Perkins DJ, Lell B, Schmidt-Ott R, Lehman LG, Luckner D, et al. Low interleukin-12 activity in severe Plasmodium falciparum malaria. Infect Immun (2000) 68:3909-15. doi:10.1128/IAI.68.7.3909-3915.2000

98. Biswas S, Karmarkar MG, Sharma YD. Antibodies detected against Plasmodium falciparum haemozoin with inhibitory properties to cytokine production. FEMS Microbiol Lett (2001) 194:175-9. doi:10.1111/j.1574-6968.2001. tb09465.x

99. Shio MT, Eisenbarth SC, Savaria M, Vinet AF, Bellemare MJ, Harder KW, et al. Malarial hemozoin activates the NLRP3 inflammasome through Lyn and Syk kinases. PLoS Pathog (2009) 5:e1000559. doi:10.1371/journal.ppat.1000559

100. Griffith JW, Sun T, McIntosh MT, Bucala R. Pure hemozoin is inflammatory in vivo and activates the NALP3 inflammasome via release of uric acid. J Immunol (2009) 183:5208-20. doi:10.4049/jimmunol.0713552

101. Dostert C, Guarda G, Romero JF, Menu P, Gross O, Tardivel A, et al. Malarial hemozoin is a Nalp3 inflammasome activating danger signal. PLoS One (2009) 4:e6510. doi:10.1371/journal.pone.0006510 
102. Luster AD. The role of chemokines in linking innate and adaptive immunity. Curr Opin Immunol (2002) 14:129-35. doi:10.1016/S0952-7915(01)00308-9

103. Jaramillo M, Godbout M, Olivier M. Hemozoin induces macrophage chemokine expression through oxidative stress-dependent and -independent mechanisms. J Immunol (2005) 174:475-84.

104. Ochiel DO, Awandare GA, Keller CC, Hittner JB, Kremsner PG, Weinberg JB, et al. Differential regulation of beta-chemokines in children with Plasmodium falciparum malaria. Infect Immun (2005) 73:4190-7. doi:10.1128/IAI.73. 7.4190-4197.2005

105. Huy NT, Trang DT, Kariu T, Sasai M, Saida K, Harada S, et al. Leukocyte activation by malarial pigment. Parasitol Int (2006) 55:75-81. doi:10.1016/j.parint. 2005.10.003

106. Ropert C, Franklin BS, Gazzinelli RT. Role of TLRs/MyD88 in host resistance and pathogenesis during protozoan infection: lessons from malaria. Semin Immunopathol (2008) 30:41-51. doi:10.1007/s00281-007-0103-2

107. Parroche P, Lauw FN, Goutagny N, Latz E, Monks BG, Visintin A, et al. Malaria hemozoin is immunologically inert but radically enhances innate responses by presenting malaria DNA to Toll-like receptor 9. Proc Natl Acad Sci U S A (2007) 104:1919-24. doi:10.1073/pnas.0608745104

108. Wu X, Gowda NM, Kumar S, Gowda DC. Protein-DNA complex is the exclusive malaria parasite component that activates dendritic cells and triggers innate immune responses. J Immunol (2010) 184:4338-48. doi:10.4049/jimmunol. 0903824

109. Coban C, Ishii KJ, Kawai T, Hemmi H, Sato S, Uematsu S, et al. Toll-like receptor 9 mediates innate immune activation by the malaria pigment hemozoin. J Exp Med (2005) 201:19-25. doi:10.1084/jem.20041836

110. Cassel SL, Eisenbarth SC, Iyer SS, Sadler JJ, Colegio OR, Tephly LA, et al. The Nalp3 inflammasome is essential for the development of silicosis. Proc Nat Acad Sci U S A (2008) 105:9035-40. doi:10.1073/pnas.0803933105

111. Rietdijk ST, Burwell T, Bertin J, Coyle AJ. Sensing intracellular pathogensNOD-like receptors. Curr Opin Pharmacol (2008) 8:261-6. doi:10.1016/j.coph. 2008.04.003

112. Ye Z, Ting JP. NLR, the nucleotide-binding domain leucine-rich repeat containing gene family. Curr Opin Immunol (2008) 20:3-9. doi:10.1016/j.coi.2008. 01.003

113. Finney CA, Lu Z, LeBourhis L, Philpott DJ, Kain KC. Disruption of Nod-like receptors alters inflammatory response to infection but does not confer protection in experimental cerebral malaria. Am J Trop Med Hyg (2009) 80:718-22.
114. Reimer T, Shaw MH, Franchi L, Coban C, Ishii KJ, Akira S, et al. Experimental cerebral malaria progresses independently of the Nlrp3 inflammasome. Eur J Immunol (2010) 40:764-9. doi:10.1002/eji.200939996

115. Barrera V, Skorokhod OA, Baci D, Gremo G, Arese P, Schwarzer E. Host fibrinogen stably bound to hemozoin rapidly activates monocytes via TLR-4 and CD11b/CD18-integrin: a new paradigm of hemozoin action. Blood (2011) 117:5674-82. doi:10.1182/blood-2010-10-312413

116. Kassa FA, Shio MT, Bellemare MJ, Faye B, Ndao M, Olivier M. New inflammation-related biomarkers during malaria infection. PLoS One (2011) 6:e26495. doi:10.1371/journal.pone.0026495

117. Tschopp J, Schroder K. NLRP3 inflammasome activation: the convergence of multiple signalling pathways on ROS production? Nat Rev Immunol (2010) 10:210-5. doi:10.1038/nri2725

118. Tyberghein A, Deroost K, Schwarzer E, Arese P, Van den Steen PE. Immunopathological effects of malaria pigment or hemozoin and other crystals. Biofactors (2013). doi:10.1002/biof.1119

Conflict of Interest Statement: The authors declare that the research was conducted in the absence of any commercial or financial relationships that could be construed as a potential conflict of interest. The editor declares that while the authors of the manuscript and himself are currently employed by McGill University, and that the author recently published a paper alongside one of the co-authors, there has been no conflict of interest during the review and handling of this manuscript.

Received: 04 November 2013; accepted: 16 January 2014; published online: 05 February 2014.

Citation: Olivier M, Van Den Ham K, Shio MT, Kassa FA and Fougeray S (2014) Malarial pigment hemozoin and the innate inflammatory response. Front. Immunol. 5:25. doi: $10.3389 /$ fimmu.2014.00025

This article was submitted to Molecular Innate Immunity, a section of the journal Frontiers in Immunology.

Copyright (c) 2014 Olivier, Van Den Ham, Shio, Kassa and Fougeray. This is an openaccess article distributed under the terms of the Creative Commons Attribution License (CC BY). The use, distribution or reproduction in other forums is permitted, provided the original author(s) or licensor are credited and that the original publication in this journal is cited, in accordance with accepted academic practice. No use, distribution or reproduction is permitted which does not comply with these terms. 